\title{
Designing Educational Activities for Preventing Social Exclusion of Refugee Children
}

\author{
Amvrosiadis Emmanouil \\ University of Aegean, Greece
}

\begin{abstract}
Social exclusion is often the case in school environments where children from different counties are the minority. This is happening due to many reasons but most of the times it relates to stereotypes, prejudices, and the ethnocentric perceptions of the native children. Today, in the multicultural society we live in, it is more imperative than ever for the school to be able to meet the needs of all students and to manage socially exclusion phenomena in innovative ways and appropriate teaching strategies. Storytelling is one of the oldest and most effective methods of learning and communication. Especially, fairy tales help to understand, respect, and appreciate diversity and promote a positive attitude towards people of different cultures, races, and religions. Through fairy tales, children experience the stories and experiences of the heroes and identify with them. Thus, fairy tales can function as a means of highlighting diversity and accepting it. In addition to that, a posting board of children's works such as paintings and drawings highlights their common points but also their differences that make them unique in a multicultural society. This paper suggests educational activities to enhance the inclusion of foreign students in school. The development of such activities focuses on kindergarten children and aims to create an environment of prevention of social exclusion that children of refugees and immigrants may face.
\end{abstract}

Keywords: diversity; fairy tales; multicultural; paintings; school 